\title{
Livro vai - Livro vem: intercâmbios de uma comunidade de leitores na correspondência de Capistrano de Abreu e João Lúcio de Azevedo (1916-1927)
}

\author{
Books come - books go: exchanges among a community of readers in the \\ correspondence of Capistrano de Abreu and Joao Lucio de Azevedo (1916-1927)
}

Paula Virgínia Pinheiro BATISTA*

Resumo: Este artigo analisa a troca de correspondências entre Capistrano de Abreu e o português João Lúcio de Azevedo, dois "homens de letras”. Ambos participaram ativamente do campo intelectual, respectivamente, no Brasil e em Portugal. Por meio das correspondências trocadas, mostra-se toda uma rede de sociabilidades que se forma em torno de trocas e práticas de leitura. Analisamos os comentários que os missivistas faziam sobre suas leituras, numa busca de apreender que tipo de apropriações eles faziam dos livros partilhados entre eles, enfocando a troca de romances e obras de ficção. O período abrange as primeiras décadas do século XX (1916-1927).

Palavras-chave: Capistrano de Abreu. Comunidade de Leitores. Correspondências.

\begin{abstract}
This paper analyzes the exchange of correspondence between the historians Joao Capistrano de Abreu and Joao Lucio de Azevedo, two "men of letters". They both participated actively in the intellectual field in Brazil and in Portugal, respectively. These correspondences show a network of sociability that was shaped around reading exchanges and skills. We analyze the comments that the writers made about their readings, in a quest to grasp what kind of appropriations were made from the books shared between them, focusing on the exchange of novels and works of fiction. The correspondences were written in the first decades of the 20th century (1916 - 1927).
\end{abstract}

Keywords: Capistrano de Abreu. Community of readers. Exchange of letters.

\footnotetext{
* Mestre em História, Doutorado em andamento. Universidade Federal do Ceará, UFC. Endereço: Av. da Universidade, 2853 - Benfica - Fortaleza - CE, CEP 60020-181. E-mail: paulavir@ig.com.br
} 
A amizade epistolar entre Capistrano de Abreu $^{1}$ e João Lúcio de Azevedo ${ }^{2}$ foi alimentada pela colaboração mútua em um espaço de quase doze anos, de 1916 a 1927. Uma colaboração que envolvia o cotidiano do ofício do historiador, composto pelas pesquisas nos arquivos, pelas leituras compartilhadas e pela prática diária da escrita. Para Bourdieu (1996, p. 42), “existir socialmente é ocupar uma posição determinada na estrutura social [...], é pertencer a grupos, é estar encerrado em rede de relações [...] que se lembram sob a forma de obrigações, de dívidas, de deveres, em suma, de sujeições”. Os círculos de convivência como institutos e academias eram lugares de sociabilidade intelectual, onde os "homens de letras” se congregavam. Contudo, Capistrano e João Lúcio elegeram o universo epistolar como espaço de sociabilidade para discorrer sobre seus trabalhos, leituras e cotidiano intelectual.

Capistrano dizia sentir-se deslocado de sua época, mas criou diversas estratégias para se inserir no campo intelectual brasileiro. As relações sociais que ele teceu no decorrer da amizade epistolar com diversos intelectuais foram fundamentais para o reconhecimento de sua posição no campo cultural. ${ }^{3}$ Capistrano se aproximou de alguns intelectuais lusitanos, como João Lúcio de Azevedo, com intuito de estabelecer intercâmbios e, também, de penetrar no mundo dos arquivos portugueses. Essas cartas revelam as práticas de pesquisa, como ir aos acervos, anotar, copiar, contratar copistas. Também descrevem as dificuldades da escrita, o domínio das fontes. Enfim, as correspondências permitem vislumbrar a trajetória de suas investigações históricas.

A tarefa do historiador era apurar fatos, buscar a exatidão dos acontecimentos. Por isso, a busca pelos documentos se tornou primordial. Capistrano localizou fontes, copiou-as, publicou documentos, crônicas e obras sobre o Brasil colonial, com o intuito de transformar esses dados e informações em textos históricos que traziam suas reflexões sobre o processo histórico vivido no país. João Lúcio também se tornou um dos grandes conhecedores da documentação existente em Portugal sobre assuntos que se referiam ao Brasil.

A busca de documentos nesses arquivos permitiu uma troca de informações entre Capistrano e João Lúcio, presentes nessas cartas, que nos mostram dois historiadores trocando confidências literárias. Assim, encontramos traços desses leitores, e vislumbramos Capistrano lendo e emitindo julgamentos literários para seus amigos, em particular para João Lúcio de Azevedo. As correspondências trocadas entre Capistrano e João Lúcio funcionam como um catálogo dos livros lidos por eles no início do século XX. Ler essas cartas de Capistrano nos oferece as dimensões sociais da República das Letras no Brasil, e por meio delas podemos vislumbrar uma classificação dos autores lidos por ele e seus círculos de amizades.

A sede de leitura de Capistrano e seu intercâmbio intelectual com João Lúcio permitiram que eles estabelecessem trocas livrescas entre os dois países. As epístolas indicam, também, um 
Livro vai - Livro vem: intercâmbios de uma comunidade de leitores na correspondência de Capistrano de Abreu e João Lúcio de Azevedo (1916-1927)

pouco do cotidiano das livrarias, apresentando parte do sortimento de livros dessas "casas de papel”.

Eram volumes variados que circulavam nesses estabelecimentos; iam desde romances até obras científicas. Os motivos de sua aquisição também variavam, indo da motivação profissional à indicação feita pelo amigo. Essa circulação de obras através do Atlântico, promovida entre Capistrano e João Lúcio, especialmente sobre História, aponta para outros lados da produção historiográfica: a própria fabricação da obra, que é impressa numa tipografia e vendida numa livraria, passando pelo processo de negociação entre autores e editores.

Os intercâmbios intelectuais marcam significativamente a escrita da História desenvolvida sob a interferência de pares intelectuais, com trocas de documentos, livros, opiniões e afetos. O diálogo epistolar estabelecido entre esses dois intelectuais estimulava a produção historiográfica de ambos, além de propiciar a colaboração mútua entre uma rede de outros intelectuais. Neste artigo, optamos por historiar a amizade epistolar com um cotidiano de leituras e livros entre esses dois historiadores.

Capistrano de Abreu tem suas singularidades como leitor, podendo ser comparado a um “devorador de livros”, um leitor insaciável, posto que dedicava horas, dias, meses para a leitura e vivia rodeado de livros, jornais, cadernos, anotações soltas em folhas espalhadas pelo seu quarto, como nos relatam seus biógrafos. ${ }^{4}$ Entre essas memórias biográficas, destacamos a de Raimundo de Menezes (1956, p. 54), que chega a afirmar que Capistrano tinha uma necessidade física de leitura e que "numa interrupção de sono, alta noite, repousa lendo. Lê no bonde, às horas da comida, em toda parte, e lê tudo, poesia, obras de ficção, direito, ciências físicas e naturais, filosofia, economia, política, e ainda lhe sobra atenção para acompanhar os jornais daqui e os principais do estrangeiro”.

Era um apaixonado pelos livros. Lia deitado numa rede, hábito de um “típico cearense”, como relata em carta a João Lúcio: “aqui no Rio fiz duas aquisições: saber do alemão o bastante para lê-lo na rede, sem estar a cada instante para recorrer ao dicionário; e através de Wappoeus, Poschel e Ratzel compreender que a geografia é tão bela ciência como difícil” (ABREU, 1977, v.2, p.38) ${ }^{5}$. Em outra carta, confessa: “encontrei à mão o terceiro volume de Castanheda e tenho estado a lê-lo na rede, como romance, apenas traçando uma ou outra marca a lápis, para facilitar o encontro de algum trecho se for preciso" (ABREU, 1977, v.2, p.69). ${ }^{6}$ A rede lhe inspirava a leitura, como revela nessa carta a João Pandiá Calógeras: “aos vaivens da rede, parece-me tudo simples e harmônico" (ABREU, 1977, v.1, p.364) ${ }^{7}$.

O gabinete de leitura de Capistrano, na velhice, era o porão de sua casa, onde ele lia estendido numa rede, e à "medida que ia lendo, atirava os livros, a esmo, no chão, pelos cantos, para 
a mesa, por forma que os volumes iam formando pilhas, a que a poeira concedia extravagantes ornatos” (MENEZES, 1956, p. 32). João Lúcio nos revela outro ambiente para as suas práticas de leitura: "no lugar onde escrevo o termômetro marca $8^{\circ}$. Aqueço as mãos de vez em quando a um esquentador elétrico que tenho junto da carteira” (Acervo do Instituto do Ceará) ${ }^{8}$. Entre esses dois lugares de leitura, a rede e a carteira, há diferenças de gestos, posturas e modos de ler. Já entre esses dois leitores, Capistrano e João Lúcio, há similaridades de gostos, textos preferidos e apreciações de leituras.

Entrevemos, nessa correspondência, várias maneiras de ler, desde uma leitura rápida de um periódico, na qual Capistrano afirma que “o trabalho do Jornal, pequeno volume, é enorme para artigo; não o li, mas passei os olhos e fiquei senhor de seu pensamento” (ABREU, 1977, v.1 p.236) ${ }^{9}$; até uma leitura atenta "li com atenção de que são dignos os dois trabalhos sobre a história do Ceará [...] gostei muito de ler seu folheto, e lucrei e aprendi bastante” (ABREU, 1977, v.1, p. $52)^{10}$; ou mesmo uma leitura como aprendizado "tenho-me cercado de livros sobre a história e a geografia de S. Paulo, e não tenho lido outra cousa e voltarei menos ignorante do que vim”(ABREU, 1977, v.1, p.245) ${ }^{11}$.

Valendo-se dessas epístolas, vislumbramos a formação de uma "comunidade de leitores”"12 estabelecida entre Capistrano, João Lúcio e uma rede de interlocução com outros intelectuais que rodeavam a dupla, como Paulo Prado, Afonso de Taunay, Guilherme Studart e outros. Nessas epístolas, encontramos variadas temáticas, desde afazeres próprios do ofício do historiador, como pesquisa de documentos em acervos, até relatos do cotidiano, incluindo aqui comentários de suas leituras diárias de livros históricos e romances.

Capistrano e João Lúcio trocavam, por meio da correspondência, ideias e opiniões sobre livros, jornais e estudos não só de suas próprias pesquisas, mas também de autores como Euclides da Cunha, Raul Pompéia, Monteiro Lobato, Machado de Assis e outros. Após a leitura, trocavam opiniões acerca do livro lido ou teciam críticas aos autores, como neste caso, quando João Lúcio elogia Machado: “tenho relido com delícia Machado de Assis, que escreve a língua do Brasil com o vocabulário dos clássicos. Em nenhum escritor moderno a nossa língua portuguesa é mais límpida e suave”(Acervo do Instituto do Ceará) ${ }^{13}$.

Mesmo elogiando o romancista, João Lúcio e Capistrano se incomodavam com a escrita de alguns ficcionistas que enveredavam pelas searas da história, como Camilo Castelo Branco e o próprio Machado de Assis, posto que, para Capistrano e João Lúcio, era fundamental a defesa de um tipo de narrativa para os eventos históricos com apuração documentada dos fatos, já que os mesmos procuravam legitimar seu ofício e estabelecer as fronteiras entre história e literatura. 
Livro vai - Livro vem: intercâmbios de uma comunidade de leitores na correspondência de Capistrano de Abreu e João Lúcio de Azevedo (1916-1927)

A disputa, no campo intelectual, por legitimidade para o relato de fatos históricos pode ser percebida nos embates que Capistrano tinha com Machado, como veremos a seguir. Em carta de 22 de julho de 1880, Machado soube que Capistrano não o encontrou em casa, então procura saber o motivo do desencontro: "fiquei incomodado quando anteontem soube que se retirara, depois de longa espera. Esperei que ontem me mandasse dizer alguma cousa, se se tratasse de negócio urgente”(ASSIS, 1997, p.7) ${ }^{14}$. Em resposta, Capistrano explica o motivo da visita:

A sua bondade é tão grande que me incomoda. Fui anteontem, mas levado antes pela simpatia que lhe dedico e pela vontade de vê-lo e ouvi-lo do que por negócio. Ia também para falarmos sobre o plano que na distribuição de fatos da História do Brasil me parece o mais próprio para tornar a narrativa una. Ontem não voltei, hoje não irei, nem tão cedo, porque às 2 horas, ao sair da Biblioteca, tenho aula no Colégio Aquino. Se soubesse a que hora encontrá-lo em sua residência, iria qualquer domingo (ABREU, 1977, v.1, p.49) ${ }^{15}$.

Além dessas visitas, os dois escritores estudaram línguas estrangeiras juntos, fizeram o curso de inglês com o Professor Eduardo Alexander e o de alemão com o Professor Carlos Jansen. Constantemente, cruzavam-se nas gazetas, livrarias, jornais e cafés da cidade do Rio de Janeiro. A amizade não impediu que Capistrano tecesse críticas ao trabalho de Machado de Assis, a ponto de afirmar em carta a Mário de Alencar, de janeiro de 1910, que “a papelada de Machado de Assis, salvo uma ou outra escapada humorística, é muito medíocre” (ABREU, 1977, v.1, p.220) ${ }^{16}$. E em artigo publicado no Jornal do Comércio, em setembro de 1920, assinala que Manuel Antônio de Almeida facilitou a carreira literária de Machado de Assis, antes “um medíocre tipógrafo da Imprensa Nacional” (ABREU, 2003a, p. 137).

Capistrano também expressou publicamente suas críticas ao romancista num artigo publicado na Gazeta de Notícias, em 1879:

É possível que o artigo que o senhor Machado de Assis dedicou à nova geração no último número da Revista Brasileira, desperte mais um protesto. Um negar-lhe-á talvez o direito de medir as raízes de alheiras conviç̧ões. Outros discutirão a conveniência de tratar de política a propósito de literatura. Outro perguntará por que não julga conveniente citar Spencer sobre as tendências literárias quem aduziu a sua opinião sobre a ineficácia da instrução como elemento moralizador. Talvez até haja quem diga que o ilustrado escritor serviu-se da linguagem para disfarçar a idéia, e que seus conceitos são tão vagos e sutis, que não se pode perceber bem o que significam (ABREU, 1976, p. 109).

Para Jefferson Cano (1998, p. 35), os dois intelectuais divergiam em suas concepções de História e Literatura. De acordo com Capistrano, 
A história quando é escrita com precipitação sem o conhecimento exato dos fatos e de todas as circunstâncias, e onde o autor, poeta ou romancista dá largas à sua imaginação deixa de ser história, é romance, é poema, deleita, agrada, distrai, mas não instrui, e não adianta idéia alguma, e livros que não adiantam idéias, de pouca utilidade são. Ou história verdadeira ou romance, tem-se a escolher, mas fazer romance em assuntos sérios, só um espírito superior disso é capaz! (ABREU, 1976, p. 39).

Segundo Capistrano, a História, como saber, estava baseada no conhecimento exato dos fatos, no uso de documentos, numa "verdade histórica”, no caráter de aprendizado e de instrução da História. Para Machado de Assis, a história era instável e imprecisa, visto que a obra literária “poderia servir à análise da sociedade [...] [já que] a história se mostra complacente com as interpretações díspares, apresentando-se volúvel” (ASSIS, 1879, p.816).

As críticas ao trabalho de Machado de Assis foram discutidas com mais detalhes em relação à obra Memórias Póstumas de Brás Cubas, publicada em 1881, numa carta escrita por Capistrano, em 10 de janeiro de 1881:

Hoje, às 7 horas da manhã, poucos momentos antes de tomar o trem de Rio Claro para Campinas, me foi entregue com a sua carta de 7, o exemplar do Brás Cubas que teve a bondade de me enviar. Li de Rio Claro a Campinas e, preciso dizer-lhe? A impressão foi deliciosa - e triste também, posso acrescentar. Sei que há uma intenção latente porém imanente a todos os devaneios, e não sei se conseguirei descobri-la. Em S. Paulo, por diversas vezes, eu e Valentim Magalhães nos ocupamos com o interessante e esfíngico X. Ainda há poucos dias, ele me escreveu: "O que é Brás Cubas em última análise? Romance? Dissertação moral? Desfastio humorístico?” Ainda o sei menos que ele. A princípio me pareceu que tudo se resumia em um verso de Hamlet de que me não lembro agora bem, mas em que figura The pale cast of thought. Lendo adiante, encontrei objeções... et je jette ma langue aux chiens. Pretendo passar dois dias em Campinas, e aqui lerei o que me falta, que infelizmente não é tanto quanto desejaria. Livros como Brás Cubas é que deveriam assumir as proporções de Rocambole ou Três mosqueteiros. Só no dia 15 partirei para o Rio (ABREU, 1977, v.1, p.49) ${ }^{17}$.

Capistrano resolve apresentar essa discussão sobre o romance de Machado de Assis para o público na sua coluna “Livros e Letras” da Gazeta de Notícias de 30 de janeiro de 1881, vinte dias depois da missiva apresentada acima. O historiador inicia seu artigo questionando o gênero literário da obra: “as Memórias Póstumas de Brás Cubas serão um romance? Em todo o caso são mais alguma coisa. O romance aqui é simples acidente. O que é fundamental e orgânico é a descrição dos costumes, a filosofia social que está implícita” (ABREU, 1976, p. 197). Segue argumentando que a filosofia usada pelo autor é triste e que este “é o primeiro a reconhecê-lo, e por isso põe-na nas elucubrações de um defunto, que nada tendo a perder, nada tendo a ganhar, pode despejar até às fezes tudo quanto se contém nas suas recordações” (ABREU, 1976, p. 198). Finaliza o artigo 
Livro vai - Livro vem: intercâmbios de uma comunidade de leitores na correspondência de Capistrano de Abreu e João Lúcio de Azevedo (1916-1927)

asseverando que "a humanidade reside no todo, mas reside igualmente no indivíduo. Como, por conseguinte, pode lesar-se a si própria?” (ABREU, 1976, p. 200).

Machado de Assis informa que o seu personagem Brás Cubas não tem nada a ver com Brás Cubas histórico, embora no romance Memórias Póstumas ele trace uma genealogia da sua família e afirme que o nome do personagem do seu romance é uma homenagem ao capitão-mor Brás Cubas.

Machado escreveu, em seu romance, que o capitão-mor Brás Cubas tinha sido fundador de São Vicente (ASSIS, 1995, p. 180), porém Capistrano afirmava que Brás Cubas era fundador de Santos (ABREU, 2003b, p. 88). Brás Cubas era um explorador português e foi o fundador da vila de Santos, governando por duas vezes a Capitania de São Vicente (1545-1549 e 1555-1556). Chegou ao Brasil no ano de 1531, com a expedição de Martim Afonso de Souza, esse considerado o fundador da vila de São Vicente.

Para Capistrano de Abreu, Brás Cubas era um personagem histórico, tanto que afirma que usará uma carta do capitão-mor nos seus Capítulos de História Colonial como fonte de pesquisa: “ainda poderia aproveitar-me da carta de Brás Cubas, descoberta pelo Alfaia, se não for a de 25 de abril de 1562, que já está impressa” (ABREU, 1977, v.1, p.23) ${ }^{18}$; ou nessa epístola na qual volta a falar de Brás Cubas: “talvez escreva nos prolegômenos do segundo de Fr. Vicente algumas linhas sobre a sesmaria concedida a Brás Cubas, comparando-a com a de Duarte Lemos”( ABREU, 1977, v.1, p.288) ${ }^{19}$.

Aqui não entraremos na discussão se Memórias Póstumas de Brás Cubas era ou não um romance ou um romance-histórico. Centramo-nos apenas na polêmica gerada entre esses dois intelectuais em torno dos seus campos de atuação, a História e a Literatura, cujo debate procurava delimitar as fronteiras entre os dois campos que se encontravam em processo de formação e construção no final do século XIX.

A circulação e troca de romances entre Capistrano e João Lúcio acendeu ainda mais a discussão em torno dos limites e das disputas entre o ofício de historiador e de ficcionista. João Lúcio, em carta de 1922, critica o romance O Judeu, no qual foi abordado um personagem histórico:

Indo ver na Torre do Tombo uns processos de cristãos novos, para estudar os inventários, deparou-se-me [sic.] a família de Antônio José da Silva. Agora já sei todos os antecedentes. O processo de Antônio José foi publicado na Rev. do Instituto, mas até hoje ninguém se ocupou dele devidamente. Há um romance de Camillo, "O Judeu”, que pretende ser uma biografia do dramaturgo infeliz, mas está cheio de erros de fato, e a fantasia, coroando a ignorância, sobrepõe se à realidade. E afinal, para o público, aquilo é a biografia real. Estou coligindo apontamentos para pôr este caso direito em um tomo de estudos avulsos que agora 
me tenta, pois que, para obra de maior fôlego não me sinto com alma (Acervo do Instituto do Ceará) $)^{20}$.

Em março de 1925, João Lúcio volta a criticar o escritor Camilo Castelo Branco:

Aqui se tem feito uma exploração enorme da memória de Camilo. As janelas das livrarias estão repletas de volumes sobre ele. E principalmente cuidam de trazer a lume a sua vida privada, deixando de parte o escritor. Camilo vivia da pena, escrevendo romance sobre romance, para granjear o pão quotidiano. Romântico em seus princípios, passou depois ao naturalismo. A composição muitas vezes é frouxa, mas em todas as obras há páginas que são modelos de boa linguagem. Entrou no campo da história, desfigurando-a para suas narrativas a seu modo. O romance "O Judeu”; de que é herói Antônio José constitui um bom exemplo do seu método. Onde lhe faltava o conhecimento dos fatos, inventava. O que se sabe em Portugal de Antônio José é colhido no romance. A verdade mora em outra parte. As "Noites de Insônia" eram séries de artigos, que ia fazendo, para as necessidades do bolso, quando já não tinha fôlego, para as dimensões maiores do romance. As "Novelas do Minho" foram, creio, seus últimos trabalhos, digo que são das melhores. Nunca li. Na polêmica era formidável; um fogo de artifício de sarcasmo e amargura. Quis ser da Academia e possuir um título de nobreza. Na academia não o quiseram; era grande de mais para lá. Como lhe recusaram o título começou a escrever, suponho que nas "Noites de Insônia”, as origens da casa de Bragança. Afinal contentaram-no. Mandei-lhe do Pará os artigos sobre o Bispo D. Frei João de L. José, que figuram nos "Estudos de História Paraense". Agradeceu, prometendo reproduzi-las na $2^{\text {a }}$ edição das Memórias do Bispo, que nunca publicou. E assinou a carta: Visconde de Correia Botelho. Isto retrata e seu estado mental dos últimos tempos (Acervo do Instituto do Ceará) ${ }^{21}$.

“História e literatura são, creio eu, les moindres de ses soucis” (ABREU, 1977, v.3, p.244) ${ }^{22}$, afirmação feita por João Lúcio em carta dirigida a Capistrano, em fevereiro de 1923. Apesar de "ser das menores preocupações”, Capistrano e João Lúcio atuaram como historiadores num momento de construção da disciplina nos seus países de origem, portanto, defendem e legitimam um modo de fazer história “científica” pautada na verdade dos fatos e fundamentada nos documentos. Por isso, criticam os ficcionistas que tentam fazer uma narrativa de eventos históricos sem uma apuração documentada dos fatos, no momento em que se estabeleciam as fronteiras entre os campos da história e da literatura.

Para além dessa disputa, os dois leitores continuam trocando confidências literárias, lendo romances, como confessa João Lúcio a Capistrano: “ando há muito apartado de literatura de imaginação, mas o romance brasileiro prende-me, por me recordar a vida passada” (ABREU, 1977, v.3, p.225) ${ }^{23}$.

Essas lembranças provocadas pela leitura levam Capistrano e João Lúcio de volta ao passado e trazem recordações longínquas, como as experiências da infância, quando eles tiveram acesso às primeiras leituras. Capistrano, em carta dirigida a Ramos Paz, conta que: “já dei ao 
Livro vai - Livro vem: intercâmbios de uma comunidade de leitores na correspondência de Capistrano de Abreu e João Lúcio de Azevedo (1916-1927)

bibliotecário seu recado sobre o Peregrino da América. Peço-lhe adquira um para mim, pois é livro que desejo possuir desde a infância, e, além disso, a primeira vez que li o nome de Vale Cabral, foi no Ceará, assinando um artigo sobre este livro, que então ainda não conseguira ver” (ABREU, 1977, v.1, p.16) ${ }^{24}$. O livro desejado na infância só foi adquirido quando Capistrano tinha 52 anos, como nos relata nessa carta de 1905: "nosso amigo Peixoto me trouxe da Europa um exemplar do Peregrino da América: era o volume 761 de um alfarrabista seu conhecido, cujo nome não me acode agora” (ABREU, 1977, v.1, p.20) ${ }^{25}$.

Em carta de 1916, Capistrano narra a João Lúcio sua experiência na meninice com a leitura em voz alta: “se ainda não conhece a Cultura e Opulência, asseguro-lhe horas de verdadeiro deleite, o capítulo lembrado de minha infância intitula-se: Do que Padece o Açúcar, etc. Saboreei o prazer divino de ouvir aquele sermão de lágrimas, lido alto, a meu pedido, por um pregador afamado” (ABREU, 1977, v.2, p.23) ${ }^{26}$.

As cartas nos mostram os hábitos de leitura de dois amigos que sentiram vontade de partilhar suas experiências por intermédio da correspondência, como na carta de 9 de março de 1918, em que Capistrano ofereceu de presente a João Lúcio seu próprio exemplar do livro Os Sertões, de Euclides da Cunha, que já estava esgotado na época, e tinha sido muito requisitado por João Lúcio: “procurei ontem na cidade Os Sertões e não achei, está esgotado, não sei se a Livraria Alves pensa em editá-lo. Mando-lhe o meu exemplar, por sinal bem pouco apresentável” (ABREU, 1977, v.2, p.83) ${ }^{27}$.

Capistrano aproveita e tece algumas apreciações sobre o autor do romance: "Euclides e Pompéia são para mim os dois primeiros escritores do Brasil moderno. Prefiro Pompéia, mas em certas cousas Euclides é superior. Com duas, três linhas rasga às vezes perspectivas admiráveis” (ABREU, 1977, v.1, p.124) ${ }^{28}$. Em sua resposta, João Lúcio agradece pelo romance, e também apresenta suas críticas ao autor:

Recebi em 18 do passado sua carta de março 8, e ontem as de 9 , 18 e 23 e $1^{\circ}$ de abril. Também os livros. Os "Sertões” dão-me uma página mais para a nova edição da "Evolução do Sebastianismo", que o Teixeira me pediu, e que sairá antes do "Vieira". Ignorava que na tragédia de Canudos houvesse um fundo de sebastianismo. Euclides da Cunha diz que ele existe em todo o sertão do norte. Inigualar escritor aquele. Tem páginas que me arrebataram, outras que me desesperam pelo rebuscado da linguagem. Fico em dúvida se os termos são do vocabulário do sertão, ou se andou o escritor a cata deles pelo dicionário (Acervo do Instituto do Ceará) ${ }^{29}$. 
Para João Lúcio, a obra Os Sertões é esclarecedora, já que apresenta uma ideia próxima da realidade do sertão. Ainda sobre obras brasileiras que abordam o sebastianismo, João Lúcio elogia também o trabalho de Taunay:

De Afonso Taunay recebi o volume da Revista do Instituto de S. Paulo com a notícia da expulsão dos jesuítas, a que ele juntou uma nota crítica de lavra própria, uma "Crônica do tempo dos Felippes”, e uma amável carta, em que V. é designado por meu ilustre amigo e seu prezadíssimo mestre (d'ele) com o que fiquei simpatizando com o homem. Na "Crônica” há dois capítulos sobre o sebastianismo que me deram na vista, quando cortava as folhas, e que li com prazer, parecendome as mais bem feitas do livro (Acervo do Instituto do Ceará) $)^{30}$.

O interesse de João Lúcio pelas mencionadas obras explica-se pelos estudos que vinha desenvolvendo para seu livro A Evolução do Sebastianismo, publicado pela primeira vez em 1918. Quando estava lendo a obra, Capistrano escreveu a seguinte apreciação:

Li, estou relendo A Evolução do Sebastianismo, para mim terreno absolutamente desconhecido. Dá idéia de Frederico Barbarroxa que deveria ressuscitar; mas neste caso tratava-se de mera lenda poética, no outro de norma de vida. Não entraria também no sebastianismo algo da história de Preste João? Em menino, ouvi falar do rei do Congo como do mais poderoso da terra; talvez seja o último avatar do Preste, a menos que não fosse um broto do messianismo escravista (ABREU, 1977, v.2, p.33) ${ }^{31}$.

Capistrano tinha o hábito de presentear os amigos íntimos com livros que lia, geralmente acompanhado de uma epístola com uma apreciação da obra presenteada. Talvez por essa prática, "sua Biblioteca encontra-se hoje muito despojada, pois Capistrano gostava de emprestar e dar livros depois de lidos” (RIBEIRO apud GONTIJO, 2004b, p. 182).

Além de presentear os amigos, também vendia seus livros quando estava se mudando ou quando queria desfazer-se de alguns volumes, como ele mesmo relata a João Lúcio, em 1923: “tenho de mudar-me até fins de julho. Vou ver se Mário compra para a Bib. da Câmara a maior parte de meus livros. Ofereceu-se a fazê-lo já há algum tempo: isto me facilitará a mudança” (ABREU, 1977, v.2, p.275) ${ }^{32}$. Em abril de 1923, Capistrano fala do alívio que terá ao vender seus livros: "posso esperar e estes livros que forem indo adiante serão outros tantos pesos que tirarei de cima. Ficarei um estudante pobre, sem cadáveres, contente com o libello no angello de qualquer pensão” (ABREU, 1977, v.2, p.447) ${ }^{33}$. Mas, alguns anos antes, ele revela sua intimidade com os livros: 
Livro vai - Livro vem: intercâmbios de uma comunidade de leitores na correspondência de Capistrano de

Abreu e João Lúcio de Azevedo (1916-1927)

Agora resolvi uma medida drástica. Sá comprou uma fazenda lá em Morro Azul, perto da Sacra Família do Tinguá, município de Vassouras. Quero mandar para lá uns dois caixões de livros. A dificuldade é escolhê-los. Cada um representa tanta cousa! Uma veleidade, um projeto, uma decepção. Neles vejo como por passeio a cronologia de meu espírito, e a impressão não é fagueira: reduz-se a lançar continuamente carga ao mar, para não evitar a submersão completa (ABREU, 1977, v.1, p.242) ${ }^{34}$.

Ao amigo, ele confessa, portanto, que cada livro representava pedaços da sua vida, como se fossem registros em um diário. Em outra, Capistrano desabafa com Paulo Prado: “acabo de saber que a casa foi vendida e terei de mudar-me a toda pressa [...] Para mim o golpe é terrível. Materialmente a mudança dos livros é um horror” (ABREU, 1977, v.2, p.445) ${ }^{35}$.

Mesmo doando e/ou vendendo seus livros, a casa de Capistrano era abarrotada de livros que velavam seu sono na solidão da vida domiciliar. Certa vez, afirmara, em carta a João Lúcio, que sua sede de leitura era ilimitada: "ler posso indefinidamente, embora pouco guarde na memória” (ABREU, 1977, v.2, p.35) ${ }^{36}$ Assim, também guardava poucos livros na sua biblioteca, que depois de lidos eram repassados aos amigos queridos. Entre os volumes doados está o romance o Ateneu, um presente para João Lúcio:

Junto um exemplar do Ateneu, o mais forte livro de nossa literatura, escrito dos 24 aos 25 anos, no espaço de três meses. O autor, um dos mais íntimos de meus amigos, brigou afinal comigo; meses depois suicidou-se. Não serve para moças. Aristarco é a caricatura desapiedada do famoso educador Abílio, Barão de Macaúbas. A concepção da vida do pobre Raul, que selou com o próprio sangue, está na pág. 264. Duas conferências no meio do volume dão sua teoria da arte e sua visão do Brasil da Abolição e da República. Vai entre os livros uma carta do Padre Hafkmeyer (ABREU, 1977, v.2, p.49) ${ }^{37}$.

João Lúcio comenta que não tinha lido ainda nenhum romance de Raul Pompéia: “o Grão Pai (sic.) que me mandou chegou-me com o que de cá lhe enviei; fico sabendo que mora aí o autor; mais um estro para florescer o calor dos trópicos. Obrigado pelos livros. Muito tenho visto citado Raul Pompéia, sem nunca se me deparar ocasião de o ler” (ABREU, 1977, v.3, p.225) ${ }^{38}$.

Em carta de $1^{\circ}$ de abril de 1920, Capistrano comenta sobre outro livro. Dessa vez, é o romance Urupês, de Monteiro Lobato, que, segundo ele, "representa o maior sucesso literário do Brasil” (ABREU, 1977, v.2, p.153) ${ }^{39}$. João Lúcio escreve elogiando o autor, em carta de 4 de fevereiro de 1920, e agradece pelo livro presenteado: “tem-me escapado agradecer-lhe o livro de Monteiro Lobato. Li com prazer, posto que às vezes me faltassem termos do vocabulário local, que muito diverge da língua do norte” (Acervo do Instituto do Ceará) ${ }^{40}$. 
Um ano antes, em 1919, Capistrano confessa ao seu amigo Afonso de Taunay que ainda não tinha lido Urupês:

Comprei Urupês de Monteiro Lobato e não podendo lê-lo mandei o exemplar ao velho Branner, bom amigo do Brasil, uma das melhores pessoas que conheço. Branner tem uma coleção brasiliana, talvez a mais completa dos Estados Unidos. Por sua morte passará à Stanford University de que foi presidente. Em carta de 11 de outubro, ontem recebida, escreve: Lendo a história de D. Isabel nas jaboticabas, contada na página do título do livro Urupês estou interessado desde já. Mais tarde lhe mandarei uma opinião mais abalizada. Conhece o autor? Se o velho Branner cumprir a promessa mandarei o juízo mais autorizado para v. transmitir-lhe. A propósito das Páginas Literárias de Rui Barbosa, remetidas na mesma ocasião, escrevi: Sinto que aquele escritor me faz, quase sempre, lembrar do chá que tem açúcar de mais. Há certas coisas neste mundo que devem ser servidas em quantidades limitadas, não acha? (ABREU, 1977, v.3, p.78) $)^{41}$.

O vaivém dos livros entre esses intelectuais demonstra a constante circulação desses objetos portadores de textos e ideias. Essas ideias podiam ser ou não usadas em suas obras, mas eram discutidas nessa troca epistolar.

Os amigos de Capistrano também pediam livros, como João Lúcio, que desejava possuir um livro de Oliveira Viana. Capistrano tornou-se, então, intermediário do pedido, escrevendo para Rodolfo Garcia: “Lúcio de Azevedo deseja possuir o livro de Oliveira Viana sobre o povo brasileiro e sua evolução. O autor frequenta o Instituto Histórico, talvez lhe fosse possível obter dele que mande a obra diretamente pelo correio, registrado, a minha custa, ça va sans dire” (ABREU, 1977, v.2, p.498) ${ }^{42}$.

Em carta a Afonso de Taunay, anos antes desse pedido, Capistrano revela que já leu a obra de Oliveira Viana e dá seu parecer: “ultimamente estou lendo Oliveira Viana sobre as Populações Meridionais, livro erudito, bem escrito, bem meditado, mas, ao menos para mim, nada convincente até a página 57, aonde cheguei” (ABREU, 1977, v.1, p.322) ${ }^{43}$. Em seguida, acrescenta uma crítica referente à ausência de seu nome na obra: “o autor não gosta de mim, deduzo pela omissão proposital de meu nome; note bem que escrevi proposital e escrevi muito propositalmente. Pouco importa se os gostos fossem os mesmos em tudo, desde muito o mundo andaria pelos ares”( ABREU, 1977, v.1, p.322) ${ }^{44}$.

João Lúcio volta a fazer pedidos, desta vez foi o $1^{\circ}$ volume da obra Documentos para a História do Brasil de Guilherme Studart, e acrescenta: “mas de nenhum modo desfalcando a própria livraria” (Acervo do Instituto do Ceará) ${ }^{45}$. Os pedidos continuavam e Capistrano parecia sempre pronto a atendê-los. Capistrano empenhava-se em encontrar os livros pedidos pelos amigos, 
Livro vai - Livro vem: intercâmbios de uma comunidade de leitores na correspondência de Capistrano de Abreu e João Lúcio de Azevedo (1916-1927)

estabelecendo uma constante troca de obras. Isso estimulava seu amigo João Lúcio, que também resolveu presentear Capistrano:

Escrevi em 11 do passado. Depois recebi suas cartas de 3 e 21. Em 25, remeti a Crônica do Pe. Simão de Vasconcelos, meu exemplar, comprado há muitos anos no Pará. Como não tenciono versar novamente o assunto de que trata, posso dispensálo. Se tiver necessidade, consultarei a obra na Biblioteca Nacional, ou na Academia (ABREU, 1977, v.2, p.235) ${ }^{46}$.

Mas não eram somente livros de outros autores que Capistrano enviava aos seus amigos. Ele também os presenteava com volumes de sua própria autoria. Presenteou seu amigo Teodoro Sampaio com um opúsculo de sua autoria editado pela casa Laemmert em 1900, intitulado Descobrimento do Brasil pelos Portugueses:

Recebi, há cerca de quinze dias, uns folhetos seus, sobre o Descobrimento do Brasil pelos Portugueses, e fiz deles a distribuição segundo as dedicatórias. Gostei muito deste seu trabalho histórico, e gostei não só do modo como a questão foi encarada como do estilo, que é de fato o que mais convém à exposição dos fatos. A parte crítica é muito interessante e, pode-se dizer, resolve as questões que a propósito do descobrimento se levantam, de modo claro e completo (ABREU, 1977, v.3, p.180) $)^{47}$.

Seu livro mais distribuído parece ter sido Rã-txa Hu-ni-ku-i, a gramática dos caxinauás. Um dos presenteados com a obra foi Alfredo Pujol: “duvido que as línguas indígenas interessem seu espírito, encaminhado para outros ideais mais elevados e bem diversos: em todo caso, vou mandar-lhe meu livresco sobre os caxinauás” (ABREU, 1977, v.3, p.66) ${ }^{48}$.

Alfredo de Carvalho também recebeu a obra e, em carta de 16 de fevereiro de 1914, agradece: "é com bastante atraso que hoje respondo às suas duas cartas e agradeço o magnífico presente do Rã-txa Hu-ni-ku-i, de que foi portador o Manuel Cícero. É um verdadeiro milagre da ciência e de paciência” (ABREU, 1977, v.3, p.299) ${ }^{49}$.

Além de livros de sua autoria, doava aos amigos as edições que organizava, anotava e publicava. Enviou: “10 exemplares [das Confissões da Bahia] para Lúcio de Azevedo distribuir em Portugal” (ABREU, 1977, v.2, p.427) ${ }^{50}$. Não foi diferente com relação à obra História do Brasil de Frei Vicente do Salvador, também distribuindo alguns exemplares. Em carta a Afonso de Taunay, informa: “junto uma lista com os nomes de pessoas de São Paulo a quem desejo oferecer exemplares de Frei Vicente, se algum dia terminar” (ABREU, 1977, v.1, p.290) ${ }^{51}$. 
Esses “presentes de papel” (VENANCIO, 2001, p. 23) e as cartas de agradecimento mostram a "prática social que se traduz no processo da escrita epistolar" (VENANCIO, 2003, p. 256). Ou seja, essa troca aponta para as práticas cotidianas estabelecidas entre intelectuais nas suas relações sociais e para o reconhecimento entre pares dentro do campo cultural. Referindo-se ao caso de Oliveira Viana, Giselle Venâncio afirma que a doação de seus livros pelo próprio autor “significa uma forma de auto-propaganda, ao mesmo tempo que indica o reconhecimento do receptor como pessoa autorizada a estabelecer uma leitura legítima” (op. cit., 2003, p. 257).

Além de doar livros, Capistrano recebia volumes de seus amigos-correspondentes, como de João Lúcio, que ofereceu ao brasileiro obras como: História do Futuro, de Padre Antônio Vieira; O Livro de Montaria, de D. João I; e Baldio, de Leotte. Além desses, recebia do amigo seus próprios trabalhos: Os Jesuítas do Grão Pará, O Marquês de Pombal e sua época (ABREU, 1977, v.2, p.13) ${ }^{52}$, História dos Cristãos Novos Portugueses e História de Antônio Vieira. Capistrano agradece os volumes recebidos:

Agradeço o exemplar dos Estudos que já lera no exemplar do Bertino: espero relêlo proximamente no meu, e também os Jesuítas e o Pombal. Agradeço também a cópia do Amador, que vou oferecer à B. Nac. em seu nome, para a Seç̧ão de Mss., aonde já existe a cópia de Pero Rodrigues. Agora pode-se comparar a versão com a da História Trágico-Marítima e a do Santuário Mariano, provavelmente bebida em Fr. Vicente do Salvador (ABREU, 1977, v.2, p.14) ${ }^{53}$.

Se pensarmos nos correspondentes de Capistrano que receberam os livros dele, veremos uma preponderância de homens de letras em torno de uma “comunidade de leitores”, cuja figura central era exercida pelo historiador. Essas obras eram discutidas e recebidas num espaço relativamente particular, a correspondência privada, um espaço bem diferente do jornal ou da revista, que são públicos. Esse espaço, um lugar no qual se poderia elogiar e criticar obras e autores no meio intelectual. Assim, no âmbito epistolar capistraneano, surgia uma “opinião pública” que discutia livros e autores privadamente e, de certa forma, legitimava uma autopromoção do "mestre e amigo” (ABREU, 1977, v.3) ${ }^{54}$ Capistrano de Abreu.

Elogios e louvores foram emitidos por seu amigo Afonso Celso, que, em carta de 30 de março de 1914, agradece

[...] o exemplar, com que foi obsequiado, da 'Gramática, texto e vocabulário dos Caxinauás’. Sem competência para julgar do merecimento dessa grande obra, já tão louvada pelos autorizados, sabe, entretanto, o mesmo abaixo assinado que ela é um monumento de perseverança, erudição e probidade científica (Acervo do Instituto do Ceará) ${ }^{55}$. 
Livro vai - Livro vem: intercâmbios de uma comunidade de leitores na correspondência de Capistrano de

Abreu e João Lúcio de Azevedo (1916-1927)

Jacinto Rebello também foi presenteado com uma obra de Capistrano e agradece "muito penhorado o seu importante livro, trabalho em que se revela um cuidado e uma paciência verdadeiramente alemães, e que ficará como mais um monumento para a reconstituição dos idiomas americanos” (Acervo do Instituto do Ceará) ${ }^{56}$.

Mas não foi só a obra Rã-txa Hu-ni-ku-i que Capistrano enviou aos seus amigos. Enviou também outras, como Capítulos de História Colonial. Doou a Herbert Smith um exemplar dessa obra, que só foi recebido sete anos depois (ABREU, 1977, v.2, p.125) ${ }^{57}$. Presenteou também Ramos Paz: "vou passar alguns dias em Sobragi, Minas. Na volta creio poder-lhe entregar um exemplar dos Capítulos de História Colonial” (ABREU, 1977, v.1, p.27) ${ }^{58}$ Esses e outros depoimentos evidenciam a posição ocupada por Capistrano no campo cultural brasileiro e a sua consagração na Historiografia Nacional.

Quando não presenteava os amigos com os volumes, Capistrano indicava a compra dos livros ou mesmo a leitura das obras. Determinadas ideias proporcionam a aquisição de determinados livros. Capistrano partilhava suas leituras com os amigos e exercia um julgamento literário de alguns autores lidos.

As leituras de fontes, documentos, crônicas e corografias históricas eram leituras de obrigação “profissional”. Como historiador, Capistrano de Abreu lia textos necessários ao ofício, como relatórios de província, correspondências de funcionários da administração pública da colônia, anais das câmaras das vilas coloniais, crônicas históricas de autores como Pero de Magalhães Gândavo, Gabriel Soares de Souza, Jaboatão, João Antônio Andreoni, Antônio Vieira, além dos estudos históricos de Frei Vicente do Salvador, Rocha Pita e Alexandre Gusmão.

Como leitor-historiador, fazia comentários variados desses textos. Entre essas leituras, destaca-se uma discussão iniciada com João Lúcio sobre a “validade e/ou qualidade histórica” dos livros escolares, em que critica Rocha Pombo, que segundo Capistrano é

Autor de várias obras, entre elas uma História do Brasil para as escolas, e outra em 8 e dez volumes. Há dois anos um amigo convidou-me a uma excursão a Araruama e Cabo Frio, aonde tem família. Levei o volume escolar e em cerca de uma semana os dois não pudemos dar conta. O obrão, em não sei quantos volumes, disse a um oficioso para passar-lhe, que era pior que peste bubônica. Este respondeu que eu não podia dizer isto, ou não era sincero. Quando houve o célebre concurso de História, que tanto amofinou o Veríssimo, vendo-se perdido quis levar a coisa a chalaça. Reprovei-o; ficou meu inimigo. Ganhamos ambos com o resultado (ABREU, 1977, v.2, p.197) ${ }^{59}$.

Capistrano não se dedicava à escrita de livros históricos no formato didático, como o fez Rocha Pombo. Preferia a atividade da pesquisa histórica. Da mesma maneira, João Lúcio também 
criticava determinados trabalhos históricos destinados ao público escolar em Portugal, como em carta em que afirma que não existiam boas corografias portuguesas para os alunos, o que havia eram compêndios escolares: "péssimos como todos os livros de ensino em Portugal” (Acervo do Instituto do Ceará) ${ }^{60}$. Capistrano confessa que os livros usados nas escolas brasileiras não são tão ruins, embora livros como do "padre [Galanti], que ficou muito meu amigo, não primava pela inteligência. Sua obra é muito usada em certas escolas. Tem a vantagem de não ser simples resumo de Varnhagen” (ABREU, 1977, v.2, p.331) ${ }^{61}$.

Essa preocupação com o público e a recepção das obras fazia Capistrano ir além da indicação de livros e leituras. Muitas vezes ele colaborou nas obras dos amigos-correspondentes. Em carta de 25 de outubro de 1922, Fernando Nobre pede a ajuda do “mestre e amigo”: “mandei arranjar esse único volume provisório, do meu livro, exclusivamente para lhe ser mostrado. Como vê, todo o livro está impresso e pronto para ser encadernado. Agora falta o que unicamente vai dar valor à obra - a palavra de Capistrano de Abreu” (Acervo do Instituto do Ceará) ${ }^{62}$. Outros pediam a ajuda do historiador para a revisão de provas, como relata Capistrano nessa carta a Mário de Alencar: "Calógeras precisa de mim, para ajudá-lo na revisão das provas de um trabalho em que está empenhado” (ABREU, 1977, v.1, p.224) ${ }^{63}$.

Júlio Ribeiro, depois de ouvir as observações de Capistrano, agradece os comentários: "há de ver que me não foi inútil a conversação que tivemos, e que aceitei todas as observações que se dignou fazer-me. Em breve receberá um exemplar da gramática de Júlio Ribeiro” (ABREU, 1977, v.3, p.268) ${ }^{64}$. Tobias do Rêgo Monteiro, convocado pelo mestre Capistrano para ouvir suas observações acerca de sua obra em conclusão, confessa:

Estou na situação de rapaz que estudou com afinco e está à espera do exame, confiado em ter trabalhado com dedicação, mas desconfiado de não ter sabido expor convenientemente quanto aprendeu, e só esperançoso de ser guiado pelo mestre, de quem espera franqueza e conselhos, sem reserva alguma (ABREU, 1977, v.3, p.259) ${ }^{65}$.

As críticas aos amigos, como Fernando Nobre, Tobias Monteiro ou Afonso de Taunay, legitimam sua posição no campo intelectual e nos auxiliam a perceber que tipo de escrita da História ele defendia. Segundo Amed (2001, p. 177), “criticando Taunay, Capistrano parecia atacar uma visão de história, ou quem sabe, os próprios canais pelos quais seriam permitidos que os textos de história viessem ao público”.

Em carta de 24 de janeiro de 1917, Capistrano sugere a João Lúcio que escreva o trabalho sobre o jesuíta Antônio Vieira em dois volumes, terminando o primeiro volume com a aventura na Amazônia e finaliza a carta com uma provocação: “quem não tem coragem, não amarra negro” 
Livro vai - Livro vem: intercâmbios de uma comunidade de leitores na correspondência de Capistrano de Abreu e João Lúcio de Azevedo (1916-1927)

(ABREU, 1977, v.2, p.26) ${ }^{66}$. Em seguida, João Lúcio admite que “a maior parte de suas sugestões foram aproveitadas [...] e nos intervalos das provas preparo o $2^{\circ}$ volume” (Acervo do Instituto do Ceará $)^{67}$.

No entanto, chega a confessar em outra missiva: “enfurece[-me] pensar que será necessário outro ano pra o segundo volume, e para finalmente descansar d'esta obsessão de um mesmo assunto por tanto tempo que já me pesa, e que me sentirei feliz de esquecer, quando a prova da última folha me sair da mão” (Acervo do Instituto do Ceará) ${ }^{68}$. Apesar de aceitar a sugestão de Capistrano, para prolongar seu trabalho em dois volumes, João Lúcio mostra-se esgotado e satisfeito com a finalização do trabalho. Tomando-se por base os agradecimentos de João Lúcio, percebe-se que Capistrano também apreciou o trabalho final:

Suas palavras acerca do "Antônio Vieira” enchem-me de orgulho, e as considero a melhor recompensa do meu trabalho; primeiramente porque a ninguém considero tão competente para julgá-lo, e tanto assim que suas insinuações, no decorrer da composição, foram sempre atendidas; depois porque V. não esconde as reservas, quando tem de as fazer. Assim aceito com júbilo seu abraço de felicitações, e profundamente desejo (Acervo do Instituto do Ceará) ${ }^{69}$.

Mesmo com o cultivo da cordialidade, nem sempre as sugestões de Capistrano eram aceitas com prontidão por João Lúcio. Quando Capistrano lhe sugeriu que escrevesse um livro sobre a História de Portugal, desde a proclamação da independência até a transplantação da Corte Portuguesa para o Brasil, João Lúcio lhe respondeu que

$$
\text { Verificar original - não é atrás ? }
$$

Sua sugestão de uma história de Portugal desde a restauração à revolução do Porto deixa-me frio. História do Pará já fiz nos “Jesuítas do Grão-Pará”; não vale a pena voltar atr. Por agora penso em remodelar e completar os estudos sobre os Cristãos Novos. Nos arquivos da Inquisição há três séculos de história, que é preciso reviver (Acervo do Instituto do Ceará) ${ }^{70}$.

Capistrano mantinha em torno de si uma grande rede de intelectuais em busca de um guia para seus estudos sobre História, e um exemplo desse tipo de “cooperação intelectual” está na sua amizade intelectual com João Lúcio. Na troca epistolar mantida entre eles, percebemos que Capistrano é visto como aquele que tem o “discurso competente”, capaz de abalizar uma obra histórica, e essa sua posição permite a formação em torno dele de uma corrente de discussão de historiadores.

É preciso observar que, no período em questão (1916-1927), Capistrano já havia escrito seus livros Descobrimento do Brasil (1883), Capítulos de História Colonial (1907) e Rã-txa-Hu-ni- 
Ku-i: a Gramática dos Caxinauás (1914), e assim se dedicava aos seus projetos de "vulgarização” bibliográfica com a organização da Série Eduardo Prado: Para Melhor Conhecer o Brasil, cujos primeiros volumes seriam publicados em 1922; a escrita de artigos publicados em jornais e revistas, como Formação dos limites do Brasil, divulgado na Revista América Brasileira em 1924; e a edição da Historia Geral do Brazil de Varnhagen, entre outros.

Além disso, a correspondência revela que nem sempre a leitura é uma prática individualizada e solitária. Capistrano e João Lúcio partilhavam suas experiências de leitura que, mesmo feitas em um espaço de foro privado, estavam articuladas com a sociabilidade da companhia letrada, já que eles trocavam livros e dividiam suas apreciações e apropriações por meio das epístolas.

Essa prática de leitura precisa ser compreendida a partir das suas conexões com a história da cultura, pensando que, em uma determinada época, elaboram-se textos segundo códigos e condicionamentos sociais da sociedade na qual são produzidos. Entretanto, não se pode esquecer que esses modos de ler têm suas particularidades, seus usos próprios do livro, e cada leitor, em particular, se singulariza com base naquilo que ele compartilha com os outros leitores que pertencem à mesma comunidade de interpretação.

As excentricidades e anedotas de um homem como Capistrano de Abreu encobriram, de certa forma, sua dedicação quase diária à difusão da leitura e dos livros. Seu labor inesgotável era a leitura, seja a crítica e sistemática de documentos e textos historiográficos seja a de obras de ficção e entretenimento. Capistrano queria difundir ainda mais a leitura no Brasil, talvez por isso tenha reeditado várias obras raras e esgotadas. Pretendia, possivelmente, arquitetar uma "identidade nacional” valendo-se da difusão das fontes e dos textos sobre a história do Brasil.

\section{Notas}

\footnotetext{
${ }^{1}$ Capistrano de Abreu nasceu em Maranguape, Ceará, em 23 de outubro de 1853 e faleceu no Rio de Janeiro a 13 de agosto de 1927. Em Fortaleza, frequentou o Colégio dos Educandos, o Ateneu Cearense e o seminário episcopal. Em 1870, seguiu para Recife com o objetivo de se formar em Direito, mas não obteve êxito. Em 1875, embarcou para o Rio de Janeiro, dedicando-se ali ao ensino e ao jornalismo, à crítica literária e aos estudos históricos. Suas principais obras são: O Descobrimento do Brasil, Capítulos de História Colonial e Hã-txa Hu-ni-ku-i: gramática, textos e vocabulários dos Caxinauás.

${ }^{2}$ João Lúcio de Azevedo nasceu em Sintra, Portugal, em 16 de abril de 1855 e faleceu em Lisboa no ano de 1934. Diplomou-se, em 1872, pelo Instituto Industrial e Comercial de Lisboa. Em 1873, partiu para o Brasil, dirigindo-se para Belém do Pará para trabalhar na Livraria do seu tio, onde depois tornou-se sócio de uma empresa de exploração de borracha e uma companhia de navegação fluvial. Em 1899, retornou ao seu país natal, passando a se dedicar, desde então, ao ofício de historiador. Suas principais obras são: Os Jesuítas no Grão-Pará: suas missões e colonização, História dos Cristão-novos Portugueses, A Evolução do Sebastianismo, História de Antônio Vieira e O marquês de Pombal e sua época.

${ }^{3}$ Cabe sublinhar que a correspondência de Capistrano de Abreu foi tema de outros estudos que tiveram como enfoque, além das cartas dirigidas a João Lúcio, também as de outros correspondentes do historiador como João Pandiá
} 
Livro vai - Livro vem: intercâmbios de uma comunidade de leitores na correspondência de Capistrano de

Abreu e João Lúcio de Azevedo (1916-1927)

Calógeras, Paulo Prado, Afonso de Taunay, Mário de Alencar, Guilherme Studart, Teodoro Sampaio (Cf. BUARQUE, 2003; GONTIJO, 2004a; GONTIJO, 2004b; BATISTA, 2006; AMED, 2001; AMARAL, 2003).

${ }^{4}$ Destacamos algumas biografias de Capistrano de Abreu: Câmara (1969); Holanda (2002); Matos (1954); Nascimento (1931); Rebello (1956).

${ }^{5}$ Carta de C.A. para J.L.A., de 19/03/1917.

${ }^{6}$ Carta de C.A. para J.L.A., de 18/09/1917.

${ }^{7}$ Carta de C.A. para João Pandiá Calógeras, de 28/09/1910.

${ }^{8}$ Carta de J.L.A. para C.A., de 26/12/1926 -

${ }^{9}$ Carta de C.A. para Mário de Alencar, de 6/09/1915.

${ }^{10}$ Carta de C.A. para João Brígido, de 20/01/1883.

${ }^{11}$ Carta de C.A. para Mário de Alencar, de 30/10/1916.

${ }^{12}$ Segundo Roger Chartier, essas "comunidades de leitores" objetivam compreender "como os mesmos textos podem ser diversamente apreendidos, manejados e compreendidos por indivíduos diferentes". Os membros dessas comunidades interpretativas compartilham estilos de leitura e estratégias de interpretação. Cf. CHARTIER, 1999, p. 11.

${ }_{13}^{13}$ Carta de J.L.A. para C.A., de 28/10/1918.

${ }^{14}$ Carta de Machado de Assis para C.A., de 22/07/1880.

${ }^{15}$ Carta de C.A. para Machado de Assis, de 23/07/1880.

${ }^{16}$ Carta de C.A. para Mário de Alencar, de 20/01/1910.

${ }^{17}$ Carta de C.A. para Machado de Assis, de 10/01/1881.

${ }^{18}$ Carta de C.A. para Ramos Paz, de 12/04/1905.

${ }^{19}$ Carta de C.A. para Afonso de Taunay, de 29/11/1917.

${ }^{20}$ Carta de J.L.A. para C.A., de 18/08/1922

${ }^{21}$ Carta de J.L.A. para C.A., de 4/03/1925 (grifo nosso)

${ }^{22}$ Carta de J.L.A. para C.A., de 11/02/1923.

${ }^{23}$ Carta de J.L.A. para C.A., de 3/06/1917.

${ }^{24}$ Carta de C.A. para Ramos Paz, de 30/11/1904.

${ }^{25}$ Carta de C.A. para Ramos Paz, de 27/01/1905.

${ }^{26}$ Carta de C.A. para J.L.A., de 18/11/1916.

${ }^{27}$ Carta de C.A. para J.L.A., de 9/03/1918.

${ }^{28}$ Carta de C.A. para J.L.A., de 8/03/1918. Raul Pompéia já era elogiado por Capistrano, como nessa carta ao Barão do Rio Branco de 1888: "ele [Domício da Gama] e Raul Pompéia são as duas vocações literárias mais vigorosas e mais brilhantes que conheço atualmente. (Carta de C.A. para Barão do Rio Branco, de 13/06/1888.

${ }^{29}$ Carta de J.L.A. para C.A., de 1/05/1918.

${ }^{30}$ Carta de J.L.A. para C.A., de 19/06/1919.

${ }^{31}$ Carta de C.A. para J.L.A., de 16/03/1917.

${ }^{32}$ Carta de C.A. para J.L.A., da oitava de Tiradentes, 1923.

${ }^{33}$ Carta de C.A. para Paulo Prado, do dia de Tiradentes, 1923.

${ }^{34}$ Carta de C.A. para Mário de Alencar, de 15/09/1915.

${ }^{35}$ Carta de C.A. para Paulo Prado, de dia das petas de 1923.

${ }^{36}$ Carta de C.A. para J.L.A., de 18/03/1917.

${ }^{37}$ Carta de C.A. para J.L.A., de 12/05/1917.

${ }^{38}$ Carta de J.L.A. para C.A., de 3/06/1917.

${ }^{39}$ Carta de C.A. para J.L.A., de 1/04/1920.

${ }^{40}$ Carta de J.L.A. para C.A., de 4/02/1920.

${ }^{41}$ Carta de C.A. para Afonso de Taunay, de 7/03/1919.

${ }^{42}$ Carta de C.A. para Rodolfo Garcia, de 7/05/1926.

${ }^{43}$ Carta de C.A. para Afonso de Taunay, de 1921.

${ }^{44}$ Carta de C.A. para Afonso de Taunay, de 1921.

${ }^{45}$ Carta de J.L.A. para C.A., de 31/10/1921.

${ }^{46}$ Carta de J.L.A. para C.A., de 3/07/1921.

${ }^{47}$ Carta de Teodoro Sampaio para C.A., de 29/06/1900.

${ }^{48}$ Carta de C.A. para Alfredo Pujol, de 29/04/1916.

${ }^{49}$ Carta de Alfredo de Carvalho para C.A., de 16/02/1914.

${ }^{50}$ Carta de C.A. para Paulo Prado, de 25/11/1922.

${ }^{51}$ Carta de C.A. para Afonso de Taunay, de 20/01/1918.

${ }^{52}$ Carta de C.A. para J.L.A., de 30/06/1916.

${ }^{53}$ Carta de C.A. para J.L.A., de 26/08/1916. 


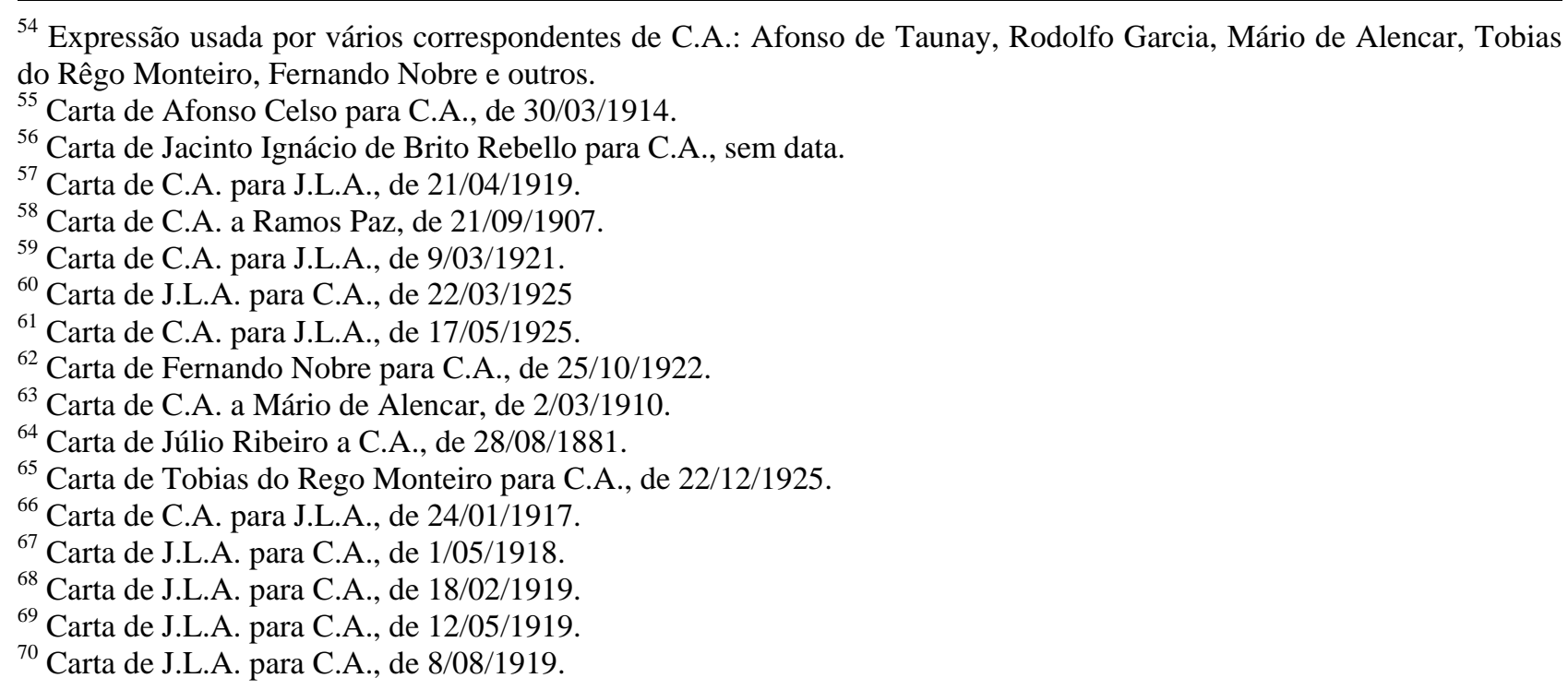

\section{Referência:}

ABREU, J. C. de. J. de A. Antonio José, o Judeu In: ABREU, J. C. Ensaios e Estudos: Crítica e História. $2^{\mathrm{a}}$ série. Brasília: Senado Federal, Conselho Editorial, 2003b, p.83-150.

Biografia. História da fundação do Império Brasileiro. Ensaios e estudos (Crítica e História). $4^{\mathrm{a}}$ série. Rio de Janeiro: Civilização Brasileira; Brasília: MEC, 1976, p.81-91.

. Livros e Letras (Seção). In: ABREU, J. C. Ensaios e Estudos (Crítica e História). $4^{\mathrm{a}}$ série. Rio de Janeiro: Civilização Brasileira / Brasília: MEC, 1976. p.104-107.

. Correspondência de Capistrano de Abreu. 3 vol. Ed. Org. e prefaciada por José Honório Rodrigues, $2^{\mathrm{a}}$ ed. Rio de Janeiro: Civilização Brasileira, INL, 1977.

. Francisco Ramos Paz. In: ABREU, J. C. Ensaios e Estudos: crítica e história. $2^{\mathrm{a}}$ série. Brasília: Senado Federal, Conselho Editorial, 2003a. p. 131-140.

. Paulística (a pretexto de uma moeda de ouro). In: ABREU, J. C. Ensaios e Estudos: crítica e história. 2a série. Brasília: Senado Federal, Conselho Editorial, 2003b. p. 87-100.

AMARAL, E. L. G. Correspondência cordial: Capistrano de Abreu e Guilherme Studart. Fortaleza: Museu do Ceará; Secretaria da Cultura e Desporto do Ceará, 2003. (Coleção Outras Histórias).

AMED, F. J. História ao portador: interlocução privada e deslocamento no exercício de escrita de cartas de João Capistrano de Abreu (1853-1927). 2001. Dissertação (Mestrado em História) Universidade de São Paulo, São Paulo, 2001.

ASSIS, M. de. A Nova Geração. In: . Obra Completa. Rio de Janeiro: José Aguilar, v.3, 1959, p. 816.

ASSIS, M. de. Correspondência. São Paulo: Globo, 1997. . Memórias Póstumas de Brás Cubas. Rio de Janeiro: Nova Cultural, 1995. 
Livro vai - Livro vem: intercâmbios de uma comunidade de leitores na correspondência de Capistrano de Abreu e João Lúcio de Azevedo (1916-1927)

BATISTA, P. V. P. Capistrano de Abreu e a correspondência feminina. Fortaleza: Museu do Ceará/ Secretaria da Cultura, 2006. (Outras Histórias, n. 41).

BOURDIEU, P. As regras da arte: gênese e estrutura do campo literário. São Paulo: Companhia das Letras, 1996.

BUARQUE, V. A. C. Escrita Singular: Capistrano de Abreu e Madre Maria José. Fortaleza: Museu do Ceará; Secretaria da Cultura e Desporto do Ceará, 2003 (Coleção Outras Histórias).

CÂMARA, J. A. S. Capistrano de Abreu. Rio de Janeiro: José Olympio, 1969.

CANO, J. Machado de Assis, Historiador. In: CHALHOUB, S.; PEREIRA, L. A. de M.. (Orgs.) A história contada: capítulos de história social da literatura no Brasil. Rio de Janeiro: Nova Fronteira, 1998. p. 35-65.

CHARTIER, R. A Ordem dos livros: leitores, autores e bibliotecas na Europa entre os séculos XVI e XVII. Brasília: Editora Universidade de Brasília, 1999.

GONTIJO, R. A reta e o círculo: amizade, projeto intelectual e construção identitária nas cartas de Capistrano de Abreu a João Lúcio de Azevedo (1916-1927). Trajetos. Revista do programa de PósGraduação em História Social e do Departamento de História da Universidade Federal do Ceará. Fortaleza: Departamento de História da UFC, vol. 3, nº 5, p. 101-128, $2004 a$.

"Paulo Amigo": amizade, mecenato e ofício do historiador nas cartas de Capistrano de Abreu. In: GOMES, Â. de C. (Org.). Escrita de Si, escrita da história. Rio de Janeiro: Editora FGV, 2004b. p. 163-193.

HOLANDA, F. Capistrano de Abreu. Fortaleza: Demócrito Rocha, 2002.

MATOS, P. G. de. Capistrano de Abreu: vida e obra do grande historiador. Fortaleza: A. Batista Fontenele, 1954.

MENEZES, R. Capistrano de Abreu: um homem que estudou. São Paulo: Edições Melhoramentos, 1956. (Coleção Grandes Vultos das Letras, n. 17).

NASCIMENTO, A. C. Capistrano de Abreu: o homem e a obra. Rio de Janeiro: Briguet, 1931.

REBELLO, E. de C. Capistrano de Abreu e a Síntese Histórica. Rio de Janeiro: Livraria São José, 1956.

VENANCIO, G. M. Na trama do arquivo: a trajetória de Oliveira Viana (1883-1951). 2003. Tese (Doutorado em História) - Universidade Federal do Rio de Janeiro, Rio de Janeiro, 2003. (mimeo)

. Presentes de papel; cultura escrita e sociabilidade na correspondência de Oliveira Viana.

Estudos Históricos. Rio de Janeiro: Fundação Getúlio Vargas, vol. 2, nº 28, p. 23-47, 2001.

Recebido em 16/08/2011 
Paula Virgínia Pinheiro Batista

Aprovado em 26/09/2011. 